\title{
Papermaking trials in a pilot paper machine with a new silica coated PCC filler
}

\author{
Ana F. Lourenço, Rogério S. Simões, Ana P. Costa, José A. F. Gamelas, Paulo J. Ferreira
}

KEYWORDS: Pilot trials, Papermaking, PCC, Silica, Strength properties

SUMMARY: The results of the papermaking tests performed in paper sheets produced in a pilot paper machine using Eucalyptus globulus bleached kraft fibres and a new filler of silica-modified PCC obtained by the sol-gel method are presented. This new filler proved already to be advantageous at lab scale and its performance is now evaluated at a pilot scale. Its application in a pilot paper machine led to results better than those obtained at lab scale. For paper sheets containing ca. $26 \mathrm{wt} \%$ of PCC-silica filler, improvements of $40 \%$ were obtained for the tensile index when compared to papers produced with the reference PCC. The optical properties were negatively affected in a magnitude similar to that of the lab trials. The improvement of the paper mechanical properties as well as the decrease in the optical properties are explained by the better bonding between the hydroxyl groups of the silica attached to the PCC particles and those of the cellulosic fibres. The present paper is of particular importance since it reveals the high potential of PCCsilica as filler for paper produced in a continuous paper machine.

ADDRESSES OF THE AUTHORS: Ana F. Lourenço (analourenco@eq.uc.pt), José A. F. Gamelas (jafgas@eq.uc.pt), Paulo J. Ferreira (paulo@eq.uc.pt): CIEPQPF, Department of Chemical Engineering, University of Coimbra, Pólo II, R. Sílvio Lima, 3030-790 Coimbra, Portugal

Rogério S. Simões (rmss@ubi.pt), Ana P. Costa (anacosta@ubi.pt): FibEnTech, Department of Chemistry, University of Beira Interior, Covilhã, Portugal

\section{Corresponding author: Paulo J. Ferreira}

The printing and writing papers grade accounts close to $32 \%$ of the total paper and board production in Europe (CEPI 2014). These papers must have excellent optical properties and dimensional stability under different hygro-thermal conditions. Besides, the paper web should have enough wet and dry tensile strength in order to enable productions speeds up to $1500 \mathrm{~m} / \mathrm{min}$, so that it becomes possible to use the best available paper technology. A high paper opacity and relatively high static rigidity require that the paper bulk is maintained at high levels, which is not in favor of intensive refining and, as a consequence, the wet web strength can be a limiting parameter (Hubbe 2014). In this way, pulp fibres with good optical and mechanical performances are required. The fibres from bleached kraft Eucalyptus globulus pulp possess excellent morphological properties to produce these paper grades, due to their small fibre length and fibre width and a relatively high fibre thickness/width ratio, which leads to a high specific surface area and a partial fibre collapse (Santos et al.
2008). However, in addition to fibres, and for economical and functional reasons, the production of printing and writing papers usually includes mineral fillers, precipitated calcium carbonate (PCC) being the most common for printing and writing fine papers. Besides contributing for the reduction of the fibre content, thus decreasing the dependence of forestry resources, PCC promotes drainage and drying in the paper machine, with clear benefits in terms of costs (Dong et. al 2008; Shen et al. 2009a). On the other hand, some paper end-use properties, like brightness, opacity, gloss, smoothness and printability are usually enhanced and its impact is often superior to that of other fillers (Shen et al. 2009a; Hubbe et al. 2008). However, as expected, the calcium carbonate mineral particles, as other mineral fillers, are detrimental to fibre bonding, and thus lead to a reduction of the paper strength. Additionally, it increases abrasion and dusting and disturbs retention which in turn increases the demand of internal sizing and retention agents. Therefore, the filler content in paper is limited to values rarely superior to $30 \%$ (Shen et al. 2009a; Raymond et al. 2004; Thorp 2005). Several strategies to overcome some of these drawbacks and increase the filler content have been pursued over the years, including the treatment/ modification of the filler surface. Examples are the modification of precipitated calcium carbonate with organic compounds such as starch, starch derivatives, carboxymethylcellulose, anionic polysaccharides, among others, and several authors claim the positive effect of these treatments on the paper properties (Chen et al. 2015; Fairchild 1995; Huang et al. 2014; Lourenço et al. 2015; Yang et al. 2013; Zhao et al. 2004). In particular, the handsheets produced with starch gel-coated PCC showed much better tensile strength than those produced from unmodified PCC, while the optical properties were not significantly affected (Zhao et al. 2004). Recently, Chen et al. (2014) using a combination of cationic chitosan and carboxymethyl chitosan to modify PCC improved brightness and opacity of the handsheets as well as the tensile strength. Some work has been also developed aiming to obtain calcium carbonate-based filler with improved acid-resistant properties which are required for papermaking in weakly acid to neutral conditions (Kim and Lee 2002; Passaretti 1991; Shen et al. 2009b). Nevertheless, when considering the modification of fillers with inorganics, just a few studies include the evaluation of the impact of the treated fillers on the mechanical properties of the papers (Shen et al. 2009a, 2009b, 2009c; Zhang et al. 2013) and in most of them only the optical properties were enhanced while the mechanical properties and/or retention did not improve.

Previously, the authors of the present paper reported the production of silica at the surface of PCC by hydrolysis of tetraethyl orthosilicate (TEOS, silica precursor) in ethanol/water solutions under alkaline conditions 
(Gamelas et al. 2011). It was proved that silica was fixed to the PCC particles as a surface film and that the amount of silica in the new materials could be controlled based on the ammonia concentration of the reaction medium, among other factors. It was suggested that the hydroxyl groups present at the surface of silica-coated PCC could provide strong physical interactions with the cellulosic fibres and thus improve the fibre-to-filler interactions and paper strength (Gamelas et al. 2011). In order to confirm this hypothesis, the same authors published another work in which the incorporation of silica-coated PCC fillers in lab handsheets led to an increase of the tensile index, tear index and internal cohesion, in comparison with the use of the unmodified PCC filler (Lourenço et al. 2013). These results were further explored so that it was possible to increase the paper filler content in 5\% without affecting the strength properties (Lourenço et al. 2014). A similar improvement of the strength properties was also observed with silica modified GCC (Lourenço et al. 2015). The present work aims at confirming the results obtained so far in laboratory by up-scaling the experiments to a pilot paper machine. The same furnish, unmodified reference PCC and modified PCC were used both at lab and pilot scale.

\section{Materials and Methods}

\section{Modified PCC synthesis}

Industrial scalenohedral PCC and silica-coated PCC particles were used as fillers in the present work. The silica-coated PCC particles were obtained by the hydrolysis/condensation of TEOS in ethanol/water solutions ( 9:1, v/v) under alkaline conditions, using ammonia as the catalyst. The synthesis was thoroughly described in a previous paper (Gamelas et al. 2011) and for the present work an upscaling $(c a .100 x)$ with the necessary adjustments was performed. The silica content in the modified materials was determined by thermogravimetry as previously reported elsewhere (Gamelas et al. 2011; Lourenço et al. 2013). It should be noted that, by using different ammonia concentrations in the reaction medium, PCCs with distinct amounts of silica can be obtained by the sol-gel method (Gamelas et al. 2011). For this work a $\left[\mathrm{NH}_{3}\right]$ of $0.3 \mathrm{M}$ was selected according to previous findings of the authors (Lourenço et al. 2013).

\section{Materials}

An industrial Eucalyptus globulus bleached kraft pulp refined up to $32{ }^{\circ} \mathrm{SR}$ was used as the cellulosic fibre source. It was disintegrated and diluted to a consistency of $1 \%$ in demineralized water. Before use, aqueous suspensions of the unmodified or modified PCC's containing $1 \mathrm{wt} \%$ of filler were prepared by adding water to PCC and stirred (20 min) to ensure a good dispersion. Alkenyl succinic anhydride (ASA) supplied by the industry was used as the internal sizing agent after stabilization by adding it to a $3 \%$ starch suspension standing at $60{ }^{\circ} \mathrm{C}$, which was prepared as previously reported elsewhere (Saraiva et al. 2010). A $0.025 \%$ aqueous solution of a linear cationic polyacrylamide $(\mathrm{L}$ -
CPAM) was prepared by dissolving the solid at $40^{\circ} \mathrm{C}$ in demineralized water and used as retention agent.

\section{Handsheets production (lab scale)}

Handsheets were produced in a batch laboratory sheet former (255/SA model, MAVIS, 120 mesh screen). The aim was to obtain a basis weight of $80 \mathrm{~g} / \mathrm{m}^{2}$ and a target filler content of $30 \mathrm{wt} \%$. The furnish was prepared with $68.9,30.0,1.0,0.1$ and $0.02 \mathrm{wt} \%$ of fibre, filler, starch, ASA and retention agent, respectively.

A mixture of the fibre suspension $(400 \mathrm{~mL})$ with the PCC suspension (100 mL) was prepared. After 120 seconds of mechanical stirring, the starch/ASA mixture (at ca. $60^{\circ} \mathrm{C}$ ) was added. The retention agent $(4 \mathrm{~mL})$ was finally added after a total time of 290 seconds and allowed to stir for more 5 seconds. The mixture was transferred into the former and, after 10 seconds of agitation, decantation and drainage were performed. The total contact time of the retention agent with the other components in the mixture was ca. $30 \mathrm{~s}$. Twelve handsheets were produced corresponding to a total consumption of 3-4 g of PCC. The sheets were collected from the web and pressed, dried and conditioned according to the ISO 5269-1 standard.

\section{Paper sheets production (pilot scale)}

The pilot paper machine (PM) comprises three stock chests, a stock pump, a wire, a couch roll, a press section and 5 dry cylinders operating at about $105^{\circ} \mathrm{C}$ (oil heaters), in addition to the vacuum pumps and auxiliary equipment and instrumentation (Fig 1). A continuous web of $0.5 \mathrm{~m}$ width was produced at a speed of $1 \mathrm{~m} / \mathrm{min}$ (the maximum velocity of the $\mathrm{PM}$ is $5 \mathrm{~m} / \mathrm{min}$ ). In the pilot tests, the refined pulp, the filler suspension and the starch/ASA mixture was added to the stock chest, while the retention agent (L-CPAM) was added inline using a peristaltic pump at the suction of the stock pump. The relative amounts of the components and contact times were the same of the handsheets lab production. One first trial was carried out at the pilot machine by using ca. $400 \mathrm{~g}$ of filler. However since the paper density obtained with this trial was much smaller than that of the lab handsheets, two other additional pilot trials (also with the same furnish composition) were performed by varying the furnish dilution and the pressing conditions at the paper machine.

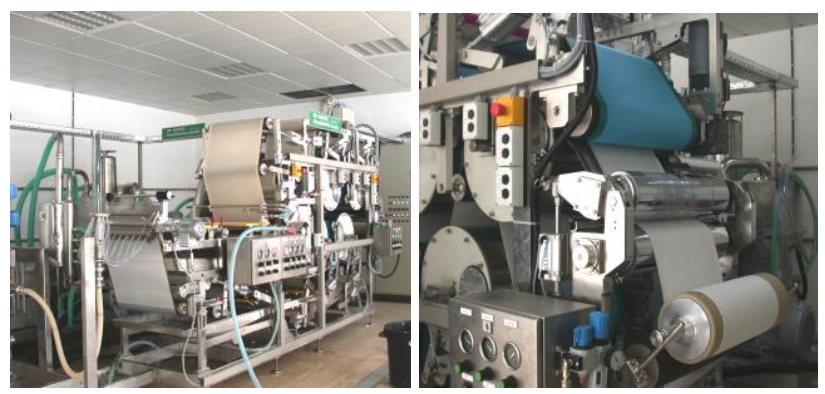

Figure 1 - Paper machine used in the pilot trials

\section{Paper properties}

For both the lab handsheets and the pilot sheets, the structural (basis weight, thickness, density and air 
permeability), mechanical (tensile, tear and burst strengths) and optical (light scattering coefficient and opacity) properties were measured according to the corresponding ISO Standard Test Methods. For the pilot trials a Geometric Mean of the Tensile or Tear Indices (GMTI) was computed (Eq.l) in order to account for the anisotropy of the paper (machine direction and cross direction, $\mathrm{MD}$ and $\mathrm{CD}$, respectively).

$$
G M T I=\sqrt{T I(C D) \times T I(M D)}
$$

Finally, the filler effective content in the sheets for each series was determined after calcination at $525{ }^{\circ} \mathrm{C}$ as described in detail elsewhere (Lourenço et al. 2013).

\section{Results and Discussion}

The present work was developed in two steps: first, the upscaling of the synthesis of the silica-modified PCC and the corresponding material characterization, comparing the results with those already published; and second the application of this modified material as filler in laboratory handsheets and in papers produced at pilot scale in a paper machine, with fully characterization of their papermaking properties.

\section{Modified PCC synthesis}

The previously reported synthesis of the modified PCC was scaled up, by using the same reaction conditions, in order to fulfill the amounts required for the pilot papermaking tests.

It was found that the material contained ca. $34 \mathrm{wt} \%$ of silica at the surface of PCC. Interestingly, it should be

noted that this is a significantly higher content of silica than that obtained in the lab synthesis previously reported (ca. 20\% of silica) (Gamelas et al. 2011). However, the increase of the silica amount was accompanied by the increase of nanosized individualized silica particles (some not attached to the PCC particles), as visible by the SEM images of Fig 2. In addition, the scaled up synthesis revealed a higher increase of the median particle size when modifying the PCC particles, respectively, from 4.2 for PCC to $8.6 \mu \mathrm{m}$ for PCC-silica (as measured in the present work by laser diffraction spectroscopy) and from 4.0 to $5.6 \mu \mathrm{m}$ (Gamelas et al. 2011).

\section{Paper production and properties}

As mentioned, the new silica-modified PCC was used as filler in papermaking. The results obtained at lab scale confirm the trend already found in previous works (Lourenço et al. 2014): for effective filler contents close to $28 \%$ and basis weight close to $80 \mathrm{~g} / \mathrm{m}^{2}$, the use of PCCsilica filler increases the tensile, tear and burst indices in comparison to the unmodified PCC. In the present work these increments were of $8 \%, 8 \%$ and $6 \%$, respectively. Contrary to the aforementioned published results the bulk did not vary when using the modified filler, which is a positive achievement.

Three different pilot trials were conducted and papers with different densities were produced. The filler content in these trials was in general smaller than that obtained in the laboratory experiments, the latter with retention values always superior to $93 \%$ (Table 1 ).

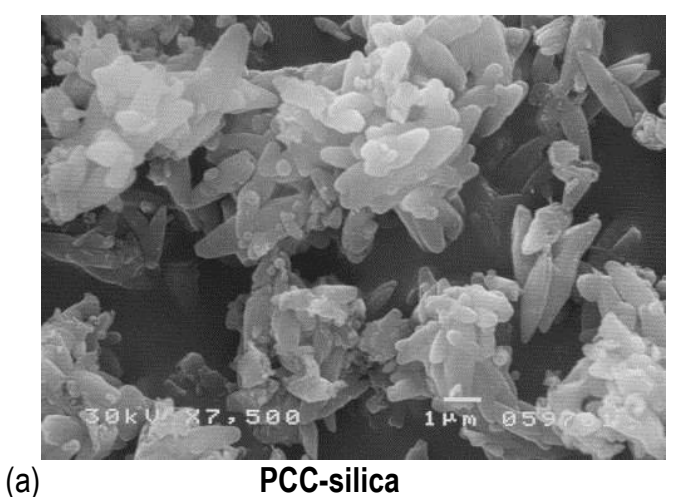

(a)
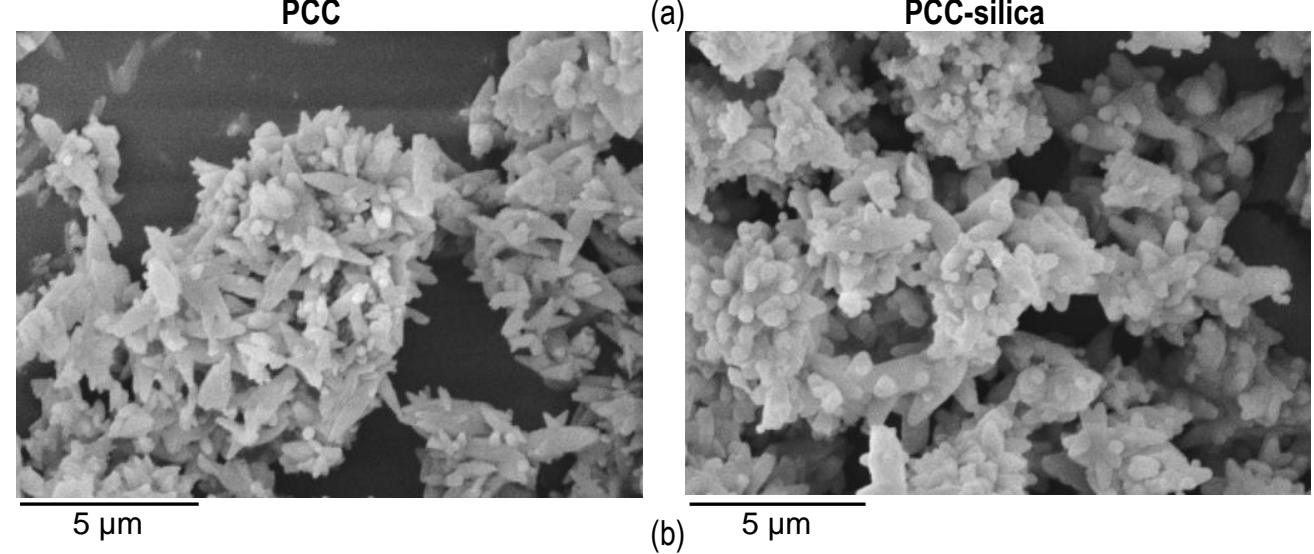

(b)

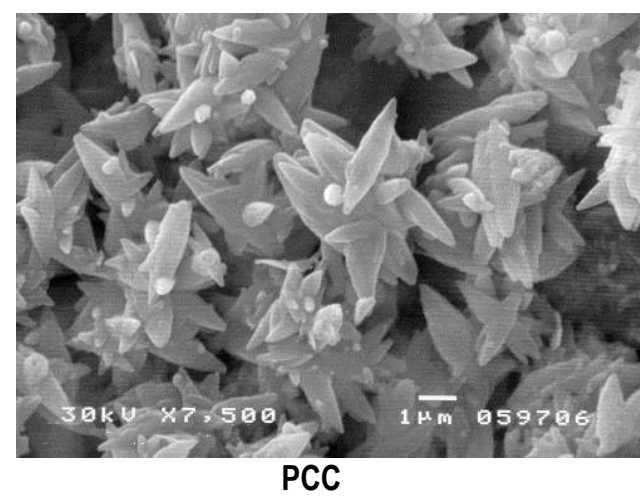

Fig 2 - SEM images (7500x) of PCC (left) and PCC-silica (right) obtained by the synthesis already published (a) and by its upscaling (b). 
Table 1 - Filler content and retention of the handsheets produced with PCC and PCC-silica at lab and pilot scale.

\begin{tabular}{ccccccccc}
\hline & \multicolumn{2}{c}{ Laboratory } & \multicolumn{2}{c}{ Pilot A } & \multicolumn{2}{c}{ Pilot B } & \multicolumn{2}{c}{ Pilot C } \\
& PCC & $\begin{array}{c}\text { PCC- } \\
\text { silica }\end{array}$ & PCC & $\begin{array}{c}\text { PCC- } \\
\text { silica }\end{array}$ & PCC & $\begin{array}{c}\text { PCC- } \\
\text { silica }\end{array}$ & PCC & $\begin{array}{c}\text { PCC- } \\
\text { silica }\end{array}$ \\
\hline Density $\left(\mathrm{g} / \mathrm{cm}^{3}\right)$ & 0.62 & 0.61 & 0.42 & 0.40 & 0.46 & 0.46 & 0.49 & 0.50 \\
Filler content (\%) & 28.0 & 28.8 & 28.6 & 25.9 & 27.7 & 26.5 & 27.2 & 26.1 \\
Retention (\%) & 93.4 & 95.8 & 95.2 & 86.3 & 92.3 & 88.3 & 90.7 & 87.1 \\
\hline
\end{tabular}

These differences are due to the distinct operating conditions of sheet forming (namely wire openings and batch vs. continuous process). Even though, worth mentioning the considerably high values attained at the pilot paper machine. Nonetheless, differently from the lab tests, the effective filler content of the papers with PCCsilica was slightly inferior to that of the papers containing unmodified PCC, which must be due to the small individualized silica particles already referred to, that are present at the furnish and certainly lost during formation.

The different paper properties as a function of the paper density are presented in Figs 3-5. As visible, in spite of the aforementioned attempts, the density of the papers produced at the paper machine was always smaller than that of the lab handsheets. In general, the air permeability decreased with the density. Besides, that of the papers produced with the unmodified or the modified PCC was similar, revealing that no relevant changes in the paper porous macro structure occurred by using the new fillers (Fig. 3).

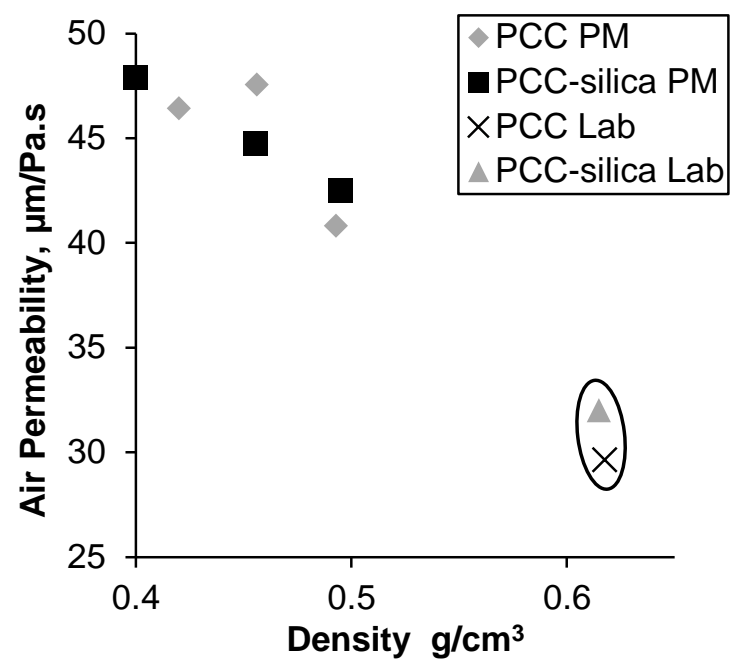

Fig 3 - Air permeability as a function of density of handsheets produced at lab and pilot trials (PM and Lab stands for pilot machine and laboratory trials, respectively).

As expected, the more compact the paper the higher the tensile index either using the original or the modified PCC (Fig 4a). Additionally, for the same density, the use of the silica-modified PCC instead of the industrial PCC resulted in an increase of the mechanical strength. This is certainly due to the positive impact of the silica modified PCC in the filler-to-fibre bonding. The slightly smaller filler content of the modified filler (Table 1) could also contribute, but only as a minor effect considering the magnitude of the increments. This was confirmed by the results obtained at lab scale, where the filler retention was the same without or with the silica-hybrid PCC and still a significant variation of the mechanical strengths occurred. This better filler-to-fibre bonding derives from the hydroxyl groups of silica which can promote hydrogen bonds with the cellulosic fibres, as detailed in previous papers (Lourenço et al. 2013; Lourenço et al. 2014). The hydrogen bonding between cellulosic fibres and the silica surface hydroxyl groups was reported before for cellulose-silica hybrids (Gamelas et al. 2012). It should be noted that the increment of the tensile strength obtained in the pilot tests was superior to that obtained at lab scale. In fact, the GMTI increased in $40 \%$ whereas the tensile of the handsheets increased only $8 \%$, which still is a remarkable achievement. As for the tear index (Fig. 4b) an evident impact of the silica modified PCC was also visible. The increase was close to $50 \%$ for the paper structures with apparent density of $0.41 \mathrm{~g} / \mathrm{cm}^{3}$ and $0.46 \mathrm{~g} / \mathrm{cm}^{3}$ but declined to ca. $21 \%$ when the paper density increases to $0.49 \mathrm{~g} / \mathrm{cm}^{3}$. This behavior can be due to the well-known tear mechanism which changes from bond failure to fibre failure, leading to this decrease (Niskanen and Kärenlampi 1998).

The paper sheet anisotropy was evaluated based on the machine and cross direction values of the tensile and tear indices, respectively, as presented in Tables 2 and 3.

Table 2 - Tensile Index (N.m/g) in the machine and cross directions (MD and $C D$, respectively) of paper sheets produced with PCC and PCC-silica as fillers.

\begin{tabular}{cccc|ccc}
\hline Density & \multicolumn{3}{c|}{ PCC } & \multicolumn{3}{c}{ PCC-silica } \\
$\left(\mathrm{g} / \mathrm{cm}^{3}\right)$ & $\mathbf{0 . 4 2}$ & $\mathbf{0 . 4 6}$ & $\mathbf{0 . 4 9}$ & $\mathbf{0 . 4 0}$ & $\mathbf{0 . 4 6}$ & $\mathbf{0 . 5 0}$ \\
\hline $\mathrm{MD}$ & 20.2 & 25.7 & 35.6 & 28.0 & 36.6 & 41.6 \\
$\mathrm{CD}$ & 14.9 & 17.1 & 19.2 & 20.3 & 23.5 & 25.0 \\
\hline $\mathrm{MD} / \mathrm{CD}$ & 1.4 & 1.5 & 1.9 & 1.4 & 1.6 & 1.7 \\
\hline
\end{tabular}

Table 3 - Tear Index $\left(\mathrm{mN} . \mathrm{m}^{2} / \mathrm{g}\right)$ in the machine and cross directions ( $M D$ and $C D$, respectively) of paper sheets produced with PCC or PCC-silica as fillers.

\begin{tabular}{cccc|ccc}
\hline Density & \multicolumn{3}{c|}{ PCC } & \multicolumn{3}{c}{ PCC-silica } \\
$\left(\mathrm{g} / \mathrm{cm}^{3}\right)$ & $\mathbf{0 . 4 2}$ & $\mathbf{0 . 4 6}$ & $\mathbf{0 . 4 9}$ & $\mathbf{0 . 4 0}$ & $\mathbf{0 . 4 6}$ & $\mathbf{0 . 5 0}$ \\
\hline $\mathrm{MD}$ & 3.9 & 4.2 & 4.3 & 5.6 & 5.6 & 5.2 \\
$\mathrm{CD}$ & 3.5 & 4.1 & 4.8 & 5.5 & 6.8 & 5.5 \\
\hline $\mathrm{MD} / \mathrm{CD}$ & 1.1 & 1.0 & 0.9 & 1.0 & 0.8 & 0.9 \\
\hline
\end{tabular}




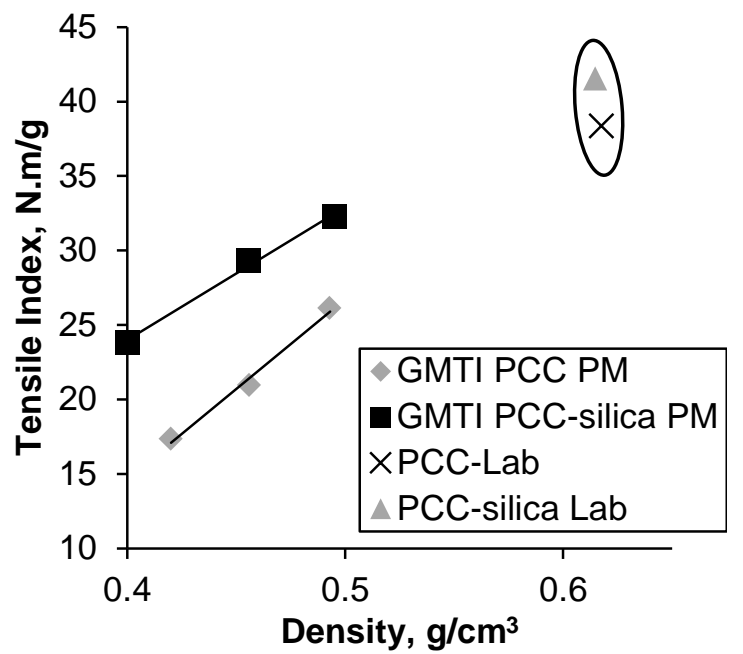

(a)

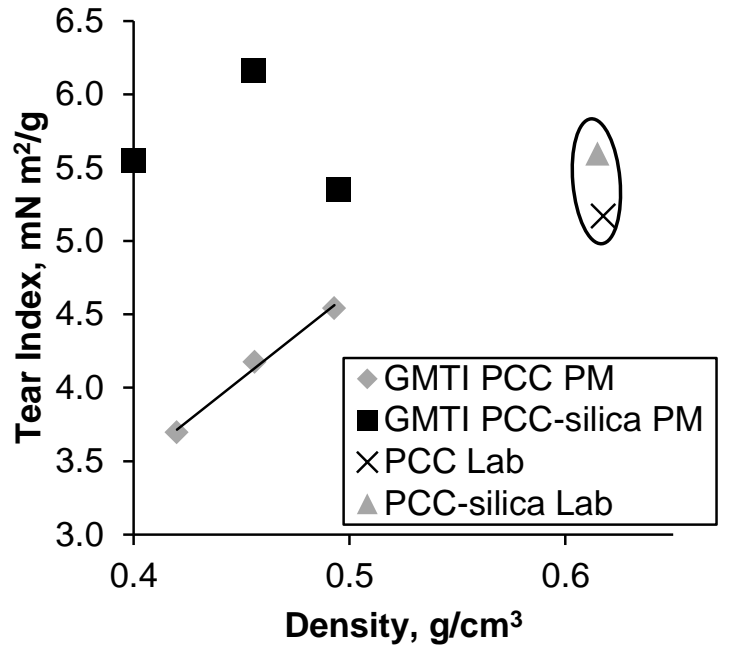

(b)

Figure 4 - Tensile (a) and tear (b) indices as a function of density of handsheets produced at lab and pilot trials (PM and Lab stands for pilot machine and laboratory trials, respectively).

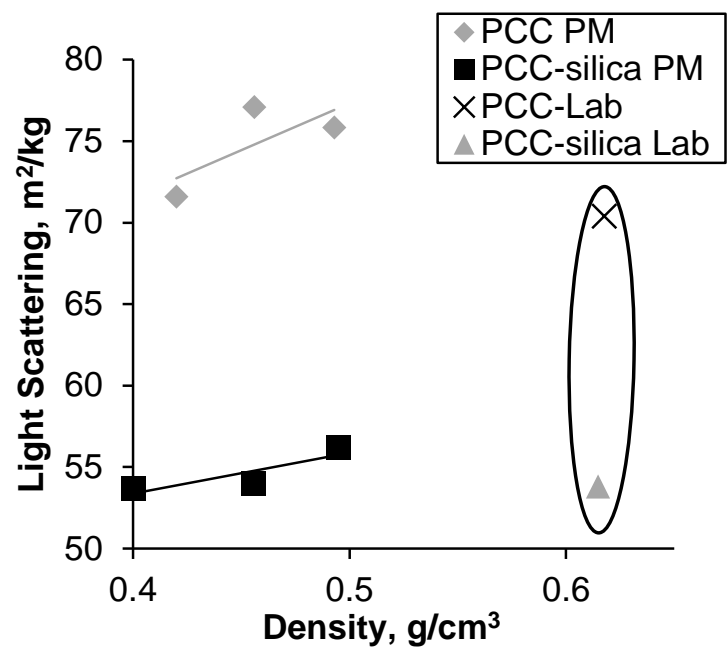

(a)

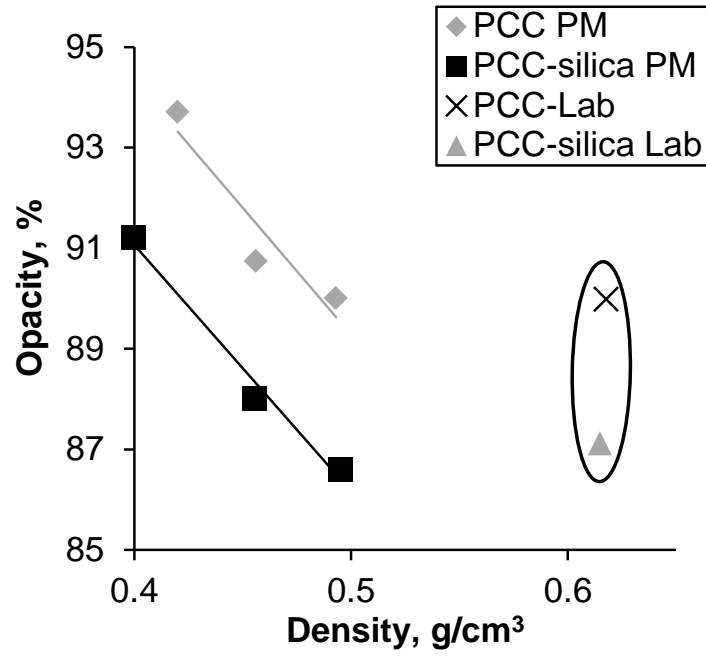

(b)

Figure 5 - Light scattering (a) and opacity (b) as a function of density of handsheets produced at lab and pilot trials (PM and Lab stands for pilot machine and laboratory trials, respectively).

The tensile index in the MD direction is always significantly higher than that in the CD direction, which is definitely due to the paper anisotropy. The fibrous suspension flow rate used was superior to the wire speed $(1 \mathrm{~m} / \mathrm{min})$ and as a consequence of this difference, the fibres were oriented in the MD direction (Niskanen 1998). As for the tear index, the MD/CD ratio is close to 1 with a slight trend to higher values in the cross direction. The presence of fillers in the paper matrix explains these results. In fact, paper sheets made only with the same fibres revealed that the tear index in the $\mathrm{CD}$ direction was higher than the one in the MD direction (9.6 and 7.3, respectively), as expected.

As for the optical properties (Fig. 5), light scattering was not significantly affected by the density but opacity decreased as a consequence of the higher compactness of the paper structure. Furthermore, it is visible that for the same density both the light scattering and the opacity decreased when replacing the original PCC by the modified one. This is in agreement with the bonding effect of the silica modified filler which, at a micro scale level, reduces the interfaces that contribute to light scattering and opacity.

Some highlights can be summarized from the previous discussion. A positive impact of a new composite of PCC with silica on the mechanical properties of paper was detected both at lab and pilot scale. This result confirms previous studies already performed in laboratory with this new filler. However, the optical properties decreased in all experiments when using the modified PCC also has detected before (Lourenço et al. 2013; Lourenço et al. 2014). Additionally, this work revealed that the improvements of the tensile and tear strength achieved at the pilot scale are much more significant than those obtained at lab scale which is a quite interesting and promising outcome for eventual use of the new filler at industrial scale. 
These results are even more relevant considering the difficulties to handle a large amount of a new material and to control the operating (papermaking) conditions in a pilot paper machine. Overall, it is concluded that at a pilot scale the PCC-silica filler is a very good material to significantly increase the bonding between fillers and fibres, which can be a solution to increase the filler content in paper.

\section{Conclusions}

The feasibility of the use of a silica-modified PCC as filler in papermaking was demonstrated in a pilot paper machine. The upscale of the synthesis of the new material demonstrated an increase of the silica content in the mineral when compared to the production already reported, although accompanied by the increment of small individualized silica particles not attached to the surface of the PCC crystals. The use of the modified PCC as filler in handsheets at lab scale had already proved to be advantageous to the paper mechanical properties, when compared to the industrial original filler, and its application to produce paper sheets in a pilot machine, as carried out in this study, revealed its huge potential as filler. In fact, the improvement of the mechanical properties was even greater than the one obtained at lab scale, using the same furnish composition. The benefits of using the silica modified PCC were explained in terms of its better bonding ability to the cellulosic fibres due to the hydroxyl groups of silica.

\section{Acknowledgements}

The authors thank FCT (Fundação para a Ciência e Tecnologia) for financial support (PTDC/EQUEQU/120578/2010).

\section{Literature}

CEPI (2014): Key statistics - European Pulp and Paper Industry, Conf. Europ. Pap Ind., Brussels,

Chen, H., Zhang, Y., Wo, Q., Yang, F., Wang, J., Guo, Y., Zheng, Q. (2015): Modified PCC used in papermaking process. BioResources 10(3), 5125-5139.

Chen, Z., Li, C., Song, Z., Qian, X. (2014): Modification of precipitated calcium carbonate filler for papermaking with adsorption of cationically derivatized chitosan and carboxymethyl chitosan. BioResources 9(4), 5917-5927.

Dong, C., Song, D., Patterson, T., Ragauskas, A., Deng, Y. (2008): Energy saving in papermaking through filler addition. Ind. Eng. Chem. Res. 47, 8430-8435.

Fairchild, G.H. (1995): Treatment of inorganic filler material for paper with polysaccharides. US Patent 5458679.

Gamelas, J.A.F., Lourenço, A.F., Ferreira, P.J. (2011): New modified filler obtained by silica formed by sol-gel method on calcium carbonate. J. Sol-Gel Sci. Technol 59, 25-31.

Gamelas, J.A.F., Evtyugina, M.G., Portugal, I., Evtuguin, D.V. (2012): New polyoxometalate-functionalized cellulosic fiber/silica hybrids for environmental applications. RSC Adv. 2, 831-839.

Huang, X., Sun, Z., Qian, X., Li, J., Shen, J. (2014): Starch/sodium oleate/calcium chloride modified filler for papermaking: Impact of filler modification process conditions and retention systems as evaluated by filler bondability factor in combination with other parameters. Ind. Eng. Chem. Res. 53, 6426-6432.

Hubbe, M.A., Pawlak, J.J., Koukoulas, A.A. (2008): Paper's appearance: A review BioResources 3(2), 627-665.

Hubbe, M.A. (2014): Prospects for maintaining strength of paper and paperboard products while using less forest resources: a review. BioResources 9(1), 1634-1763.

Kim, D.S., Lee, C.K. (2002): Surface modification of precipitated calcium carbonate using aqueous fluosilicic acid. Appl. Surf. Sci. 202(1-2), 15-23.

Lourenço, A.F., Gamelas, J.A.F., Zscherneck, C., Ferreira, P.J. (2013): Evaluation of silica-coated PCC as new modified filler for papermaking. Ind. Eng. Chem. Res. 52(14), 50955099.

Lourenço, A.F., Gamelas, J.A.F., Ferreira, P.J. (2014): Increase of the filler content in papermaking by using a silicacoated PCC filler. Nord. Pulp Paper Res. J. 29, 240-245.

Lourenço, A.F., Gamelas, J.A.F., Sequeira, J., Ferreira, P., Velho, J.L. (2015): Improving paper mechanical properties using silica modified ground calcium carbonate as filler. BioResources 10(4), 8312-8324

Lourenço, A.F., Gamelas, J.A., Ferreira, P.J. (2015) Precipitated calcium carbonate modified by the layer-by-layer deposition method - Its potential as papermaking filler. Chem. Eng. Res. Design 104, 807-813.

Niskanen, K. (1998). Book 16 Paper Physics, Papermaking Science and Technology. Published by the Finnish Paper Engineers' Association and TAPPI.

Passaretti, J.D (1991): Acid-stabilized calcium carbonate, process for its production and method for its use in the manufacture of acidic paper, US Patent 5043017.

Raymond; L., Turcotte, R., Gratton, R. (2004): The challenges of increasing filler in fine paper. Paper Technol. 45(6), 34-40.

Santos A., Amaral, M.E., Vaz, A., Anjos O., Simões, R. (2008): Effect of Eucalyptus globulus wood density on papermaking potential. Tappi J. 7(5), 17-24.

Saraiva, M.S., Gamelas, J.A.F., de Sousa, A.P.M., Reis, B.M., Amaral, J.L., Ferreira, P.J. (2010): A new approach for the modification of paper surface properties using polyoxometalates. Materials 3, 201-215.

Shen, J., Song, Z., Qian, X., Liu, W. (2009a): Modification of papermaking grade fillers: a brief review. Bioresources 4, 11901209.

Shen, J., Song, Z., Qian, X., Liu, W. (2009b): Modification of precipitated calcium carbonate filler using sodium silicate/zinc chloride based modifiers to improve acid-resistance and use of the modified filler in papermaking. Bioresources 4, 1498-1519. 
Shen, J., Song, Z., Qian, X., Liu, W. (2009c): A preliminary investigation into the use of acid-tolerant newspaper. Bioresources 4, 1178-1189.

Thorp, B. (2005): Engineered fillers: an agenda 2020 goal. Solutions People, Processes Pap, May 88(5), 45-48.

Yang, H., Qiu, L., Qian, X., Shen, J. (2013): Filler modification for papermaking with cationic starch and carboxymethylcellulose: A comparative study. BioResources 8(4), 5449-5460.

Zhang, M., Song, S., Wang, J., Sun, J., Li, J.Z., Ni, Y., Wei, X. (2013): Using a novel fly ash based calcium silicate as a potential paper filler. BioResources 8(2), 2768-2779.

Zhao, Y., Zeshan, H., Ragauskas A., Deng, Y. (2004): Improvement of paper properties using starch-modified precipitated calcium carbonate filler. Tappi J., 2(4), 3-7. 